\title{
The First Lithium-ion Battery with Ionic Liquid Electrolyte Demonstrated in Extreme Environment of Space
}

\section{Masaki YAMAGATA, ${ }^{a, b, *,+}$ Kohei TANAKA, ${ }^{c}$ Yoshihiro TSURUDA, ${ }^{d}$ Yoshitsugu SONE, ${ }^{c, e,+}$ Seisuke FUKUDA, ${ }^{e}$ Shinichi NAKASUKA, ${ }^{d}$ Michiyuki KONO, ${ }^{b}$ and Masashi ISHIKAWA ${ }^{a, b,+}$}

a Department of Chemistry and Materials Engineering, Faculty of Chemistry, Materials and Bioengineering, Kansai University, 3-3-35 Yamate, Suita, Osaka 564-8680, Japan

b iElectrolyte LLC, Knowledge Capital North Bld. 901, Grand Front Osaka,

3-1 Ofukacho, Kita-ku, Osaka 530-0011, Japan

c The Graduate University for Advanced Studies, SOKENDAI,

3-1-1 Yoshinodai, Chuo-ku, Sagamihara 252-5210, Japan

d Department of Aeronautics and Astronautics, The University of Tokyo,

7-3-1 Hongo, Bunkyo-ku, Tokyo 113-8656, Japan

e Institute of Space and Astronautical Science, JAXA,

3-1-1 Yoshinodai, Chuo-ku, Sagamihara 252-5210, Japan

* Corresponding author: yamagata@kansai-u.ac.jp

\begin{abstract}
A prototype lithium-ion battery with a bis(fluorosulfonyl)imide (FSI)-based ionic liquid electrolyte was developed. The prototype was mounted on a demonstration module of the "Hodoyoshi-3" microsatellite, which was successfully launched on June 20, 2014. Qualification tests for space application, including radiation tolerance and vacuum tests, revealed negligible degradation of the ionic liquid-based lithium-ion battery (IL-LIB) cell. According to the flight data, the IL-LIB cell can exist stably in an ultra-high vacuum environment despite its thin and flexible pouch casing without any rigid anti-vacuum reinforcements. Furthermore, the power unit showed the same charge-discharge performance as that predicted by the charge-discharge behavior of an identical cell on the ground, suggesting that the IL-LIB cell maintains performance in high vacuum a microgravity environment. These results prove that LIB cells with FSI-based ionic liquids can be used as a power source for space applications.
\end{abstract}

(C) The Electrochemical Society of Japan, All rights reserved.

Keywords : Lithium-ion Battery, Ionic Liquids, Bis(fluorosulfonyl)imide, Space Application

\section{Introduction}

The global lithium-ion battery (LIB) market has rapidly grown since they first appeared in 1991, spurred in part by the development of portable electronics. Compared with conventional aqueous electrolyte-base secondary batteries, LIBs offer high energy density, high operation voltage, wide operation temperature, and long cycle life without memory effect. ${ }^{1,2}$ In recent times, LIBs have also attracted much attention because of their potential use in electric and hybrid electric vehicles, as well as renewable and $\mathrm{CO}_{2}$-neutral primary energy sources, which will ensure continued demand for advanced LIBs in the near future. ${ }^{2-6}$ LIBs are also promising for space applications where energy storage devices with high specific energies are strongly desired.

The first LIB having specific energy density of approximately $25 \mathrm{Wh} \mathrm{kg}^{-1}$ flew to space in the United Kingdom's small "STRV1d" satellite, which was launched on November 16, 2000 but failed two weeks after launch. Since then, the use of LIBs for space applications to replace aqueous-electrolyte-based batteries, such as $\mathrm{Ni}-\mathrm{Cd}, \mathrm{Ni}-\mathrm{MH}$, and $\mathrm{Ni}-\mathrm{H}_{2}$ batteries, has been applied to the space programs. The European spacecraft "Proba-1," which was launched on October 22, 2001, included a $104 \mathrm{Wh} \mathrm{kg}^{-1}$ battery module constructed with $9 \mathrm{Ah}$ LIBs, and for the first time, successfully operated stably for more than 1,000 cycles. ${ }^{7,8}$ Launched in 2002, the French satellite "Stentor" was powered by only two 40 Ah LIB modules produced by SAFT. ${ }^{9}$ The Japan Aerospace Exploration Agency (JAXA) also chose LIBs as a main bus battery for the

†The Electrochemical Society of Japan, Individual Member. interplanetary spacecraft "Hayabusa"10,11 and a piggy-back satellite "Reimei"12. A 13.2 Ah $\mathrm{LiCoO}_{2}$-based LIB module was installed in the "Hayabusa" spacecraft for its long journey to and from the asteroid "Itokawa." The "Reimei" satellite contains a 3.0 Ah $\mathrm{Li}_{x} \mathrm{Mn}_{2} \mathrm{O}_{4}$-based LIB pouch cell, which has been in operation for more than 10 years and has achieved 50,000 charge-discharge cycles. Other long-term missions that are being attempted are as follows: twin NASA's Mars Rovers, "Spirit" and "Opportunity" had significantly contributed to their Mars exploration programs since 2003. ${ }^{13-15}$ The rovers, which have two parallel LIB packs in which eight $10 \mathrm{Ah}$ cells are connected in series survived in the severe environment on Mars for more than 6 years, and "Opportunity" has been still surveyed on the Mars land. The success of the NASA's Mars mission proved the impressive usability and durability of the use of lithium-ion batteries as a power storage apparatus for long-life planetary probe mission. Furthermore, the European spacecraft "Rosetta," the first spacecraft to make a soft landing on a comet, utilizes a $1070-W h$ LIB comprising Sony's $18650 \mathrm{HC}$ cells. The satellite has been traveling since 2004 and is currently fulfilling its mission. These long-term missions have proved the remarkable advantages of LIBs for space applications.

In general, batteries for space applications should be designed with careful consideration of an ultra-high vacuum environment and the violent vibration during lift-off. Thus, because of the use of liquidus and volatile electrolytes, which can cause serious problems such as electrolyte leakage, expansion of the cells, and deterioration of cell performance, the cells usually require reinforcement with a rigid anti-vacuum exterior or resin mold. ${ }^{12,16}$ To overcome the disadvantages of liquid electrolytes, the use of polymer solid 
electrolytes in the construction of space batteries has been identified. Polymer electrolytes can offer LIB cells in a pouch format, which allows geometric flexibility and can reduce weight and space requirements for spacecraft and spacesuits that are inherently volume limited. ${ }^{17}$ However, in general, polymer electrolytes are less advantageous in terms of their low ionic conductivity and large internal resistance, which limits their use in mission equipment that requires high current density.

Room temperature ionic liquids, such as 1-ethyl-3-methylimidazolium bis(trifluoromethylsulfonyl)imide, have attracted growing interest as next-generation electrolytes for energy storage devices including LIBs, because of their advantageous properties such as electrochemical stability, wide liquidus temperature range, and acceptable ionic conductivity. ${ }^{18-24}$ With regard to safety, the application of ionic liquids in LIBs exploits their lower flammability and non-volatility. Such advantages should also be beneficial for LIBs in electronics, vehicle and aerospace applications. Thus, many reports have demonstrated the use of ionic liquid electrolytes and shown their high potential for the development of LIBs. ${ }^{20-30}$ However, compared with conventional organic solvent-based electrolytes, most of these ionic liquids, have drawbacks, such as relatively high viscosity and low ionic conductivity resulting in lower charge-discharge rate capability and poor low-temperature characteristics in LIB cells. We successfully identified a promising ionic liquid that contains bis(fluorosulfonyl)imide $\left(\mathrm{FSI}^{-}\right)$as an anion. This liquid with a lithium salt offers incredible LIB performance without any volatile organic additives. Despite the relatively high viscosity and low ionic conductivity of the electrolyte, it realizes reversible, stable cycling, and fast charge-discharge performance of both positive and negative electrodes. ${ }^{31-36}$ The highrate capability and high-stability of an LIB based on a FSI-based ionic liquid electrolyte is presumably because of a low-resistive electrode-electrolyte interface formed between $\mathrm{Li}^{+}$and $\mathrm{FSI}^{-} .37,38$

We report the development of an LIB cell with an FSI-based ionic liquid electrolyte, which was mounted on a demonstration module of the "Hodoyoshi-3" microsatellite. To the best of our knowledge, this is the first report that shows the practicability of an ionic liquid as an electrolyte for LIBs in space.

\section{Overview of the "Hodoyoshi-3" Microsatellite}

The "Hodoyoshi-3" microsatellite (Fig. 1) was one of the four satellites that was developed in a consecutive series based on "Hodoyoshi reliability engineering." The objective was to improve traditional satellite construction procedures, which typically have incurred enormous costs and development times greater than five years. ${ }^{39,40}$ This new methodology will enable the development of $50 \mathrm{~kg}$-class satellites efficiently at extremely low cost (less than three million USD) within a short period (approximately two years) by adjusting performance and reliability levels to meet customer requirements.

"Hodoyoshi-3" specifications are summarized in Table 1. The satellite carries scientific and engineering apparatuses and $10-\mathrm{cm}$ cubic demonstration modules mounted on the top of the satellite (Fig. 2). The demonstration modules perform various educational, scientific, and technological missions. "Hodoyoshi-3" was successfully launched on a Dnepr launch vehicle at the Yasny Launch Base in Russia (4:11 am, June 20, 2014 Japan Standard Time).

\section{Experimental}

\subsection{Ionic liquid-based LIB pouch cells}

We developed prototype $\mathrm{LiNi}_{1 / 3} \mathrm{Mn}_{1 / 3} \mathrm{Co}_{1 / 3} \mathrm{O}_{2}$ (NMC) graphite pouch cells with capacities of 0.4 and $1.0 \mathrm{Ah}$. The LIB cell specifications are summarized in Tables 2 and 3. The $0.4 \mathrm{Ah}$ cells with three types of ionic liquid electrolytes, i.e., LiTFSI/EMImFSI,

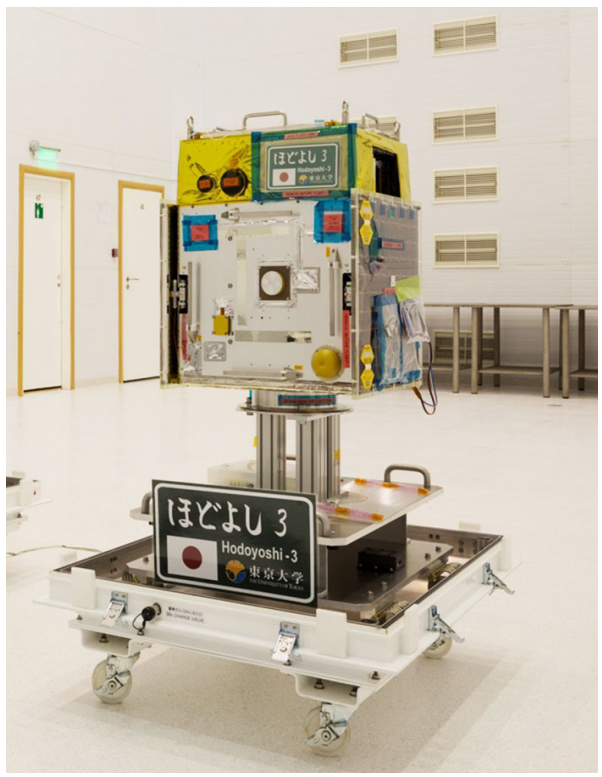

Figure 1. (Color online) Photo of the flight model of microsatellite "Hodoyoshi-3" [used by permission of Hodoyoshi-3 and -4 Project].

Table 1. Specifications of "Hodoyoshi-3".

\begin{tabular}{ll}
\hline International Designation Code & 2014-033-F \\
\hline Launch information & \\
\hline $\begin{array}{l}\text { Launch date } \\
\text { Launch site } \\
\text { Launch vehicle }\end{array}$ & $\begin{array}{l}\text { Yasny, Russia } \\
\text { Dnepr }\end{array}$ \\
\hline Size and weight & \\
Size & W 500 $\times$ D 500 $\times$ H 700 mm \\
Weight & 56 kg \\
\hline Orbit & \\
Type & Sun synchronous \\
Altitude & Perigee: $612 \mathrm{~km}$ \\
Inclination & Apogee: $665 \mathrm{~km}$ \\
Period for revolution & 97.969 degrees \\
\hline Attitude control & 97.48 min \\
Method & \\
Sensors & Three-axis stabilization \\
Actuators & GPS, Sun Sensors, Magnetometer, \\
& FOG, Star Sensor \\
\hline & Magnetic Torquers, Reaction \\
& Wheels \\
\hline
\end{tabular}

LiFSI/EMImFSI, and LiFSI/MPPyrFSI $\left(\mathrm{MPPyr}^{+}=N\right.$-methyl- $N$ propylpyrrolidinium), were prepared to clarify the effect of the constituent ions on the radiation stability of the corresponding cells. EMImFSI and MPPyrFSI were produced by Dai-ichi Kogyo Seiyaku Co. Ltd. (Kyoto, Japan) and contain less than $10 \mathrm{ppm}$ $(\mathrm{w} / \mathrm{w})$ moisture and less than $2 \mathrm{ppm}(\mathrm{w} / \mathrm{w})$ halides and alkali metal ion impurities. An LiFSI salt was also provided by Dai-ichi Kogyo Seiyaku. LiTFSI was purchased from Kanto Kagaku Co. Ltd. The ionic liquid electrolytes were prepared by dissolving the Li salts in ionic liquids at room temperature in a glove box, followed by vacuum drying at $80^{\circ} \mathrm{C}$ for $24 \mathrm{~h}$. The $1.0 \mathrm{Ah}$ cell with the LiFSI/ MPPyrFSI electrolyte was used to investigate its high-vacuum 
(a)
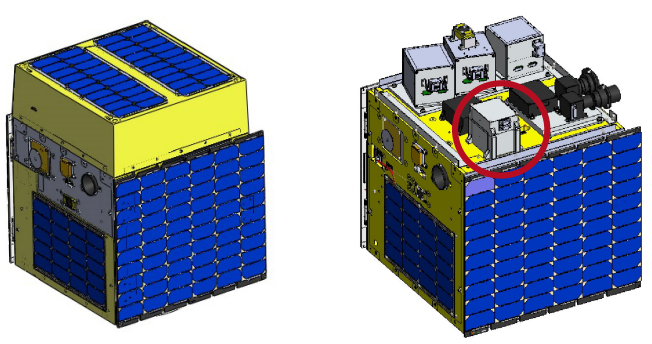

(b)

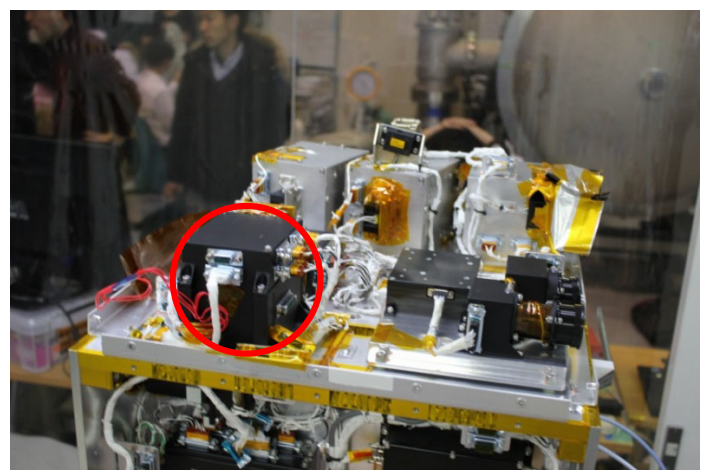

Figure 2. (Color online) (a) Location of the demonstration module on the "Hodoyoshi-3" microsatellite [schematic illustration of the "Hodoyoshi-3" used by permission of Hodoyoshi-3 and -4 Project]. The demonstration module was installed on the top surface of the satellite's main body; (b) Photograph of all hosted payloads, including the demonstration module for the in-orbit experiment of the IL-LIB cells. The black demonstration module is indicated by a red circle.

Table 2. Specifications of the ionic liquid-based lithium-ion battery for the radiation test.

\begin{tabular}{ll}
\hline Capacity & $0.4 \mathrm{Ah}$ \\
Discharge voltage (ave.) & $3.7 \mathrm{~V}$ \\
Cut-off voltage & 2.7 (lower limit)/4.2 V (higher limit) \\
$\begin{array}{l}\text { Materials } \\
\quad \text { Positive material }\end{array}$ & $\mathrm{LiNi}_{1 / 3} \mathrm{Mn}_{1 / 3} \mathrm{Co}_{1 / 3} \mathrm{O}_{2}$ (NMC) \\
$\quad$ Negative material & Graphitized carbon \\
& a) LiTFSI/EMImFSI \\
\multicolumn{1}{|l}{ Electrolyte } & b) LiFSI/EMImFSI \\
& c) LiFSI/MPPyFSI \\
Mass of one cell & $16.8 \pm 0.2 \mathrm{~g}$ \\
Size of one cell & W $56 \times \mathrm{L} 87 \times \mathrm{H} 2.5 \mathrm{~mm}$ \\
\hline
\end{tabular}

Table 3. Specifications of the ionic liquid-based lithium-ion battery for vacuum test and flight.

\begin{tabular}{|c|c|}
\hline Capacity & $1.0 \mathrm{Ah}$ \\
\hline Discharge voltage (ave.) & $3.7 \mathrm{~V}$ \\
\hline Cut-off voltage & 2.7 (lower limit)/4.2 V (higher limit) \\
\hline \multicolumn{2}{|l|}{ Materials } \\
\hline Positive material & $\mathrm{LiNi}_{1 / 3} \mathrm{Mn}_{1 / 3} \mathrm{Co}_{1 / 3} \mathrm{O}_{2}$ \\
\hline Negative material & Graphitized carbon \\
\hline Electrolyte & LiFSI/MPPyFSI \\
\hline Mass of one cell & $39.4 \pm 0.1 \mathrm{~g}$ \\
\hline Size of one cell & W $56 \times$ L $87 \times$ H $7.4 \mathrm{~mm}$ \\
\hline
\end{tabular}

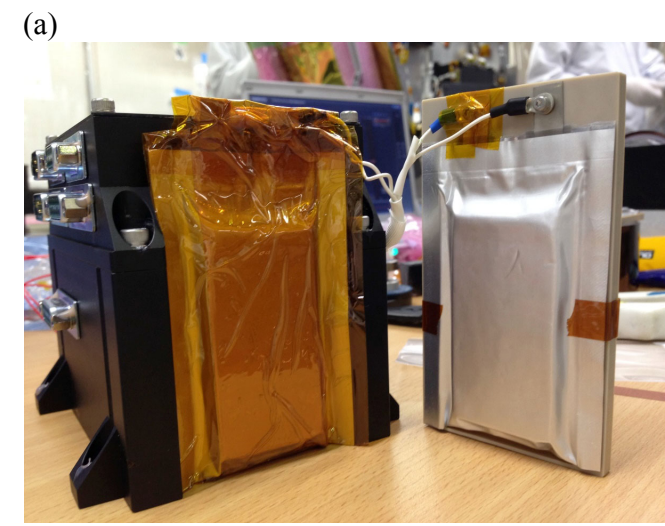

(b)

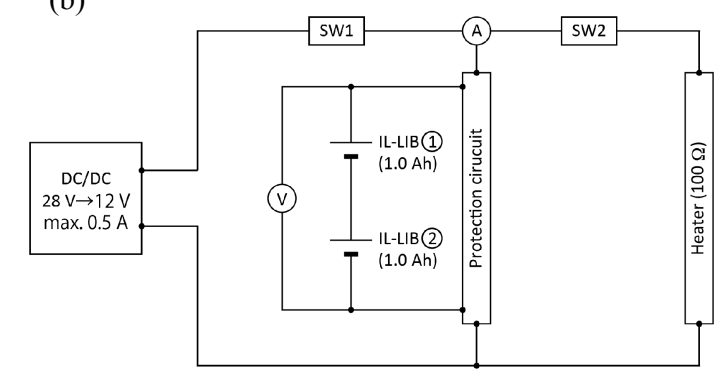

Figure 3. (Color online) (a) Photograph of the IL-LIB cells mounted on the demonstration module; (b) circuit schematic for the battery evaluation system, including power unit, which was constructed by connecting two of the IL-LIB cells in series.

sealing performance. The same $1.0 \mathrm{Ah}$ cell was employed as a flight model (FM) and installed in the battery evaluation module on the satellite.

\subsection{Qualification test for EM cell}

All materials used to construct a satellite should survive highlevel radiation in an ultra-high vacuum environment. First, the radiation tolerance of three $0.4 \mathrm{Ah}$ cells was evaluated by applying ${ }^{60} \mathrm{Co}$ gamma ray radiation (Radiation Research Center, Osaka Prefecture University) at a dose of $12 \mathrm{krad}$ for $1 \mathrm{~h}$, which corresponds to a total radiation dose of more than one year in earth orbit. Furthermore, a high-vacuum chamber (The University of Tokyo) was used to simulate operation in a space environment. Several 1.0 Ah cells were placed inside the chamber and exposed to reduced atmospheric pressure of $10^{-4} \mathrm{~Pa}$ for $80 \mathrm{~h}$. After the vacuum test, the cell impedance was measured using a portable, handheld battery tester (Battery HiTester 3554, Hioki E.E. Corp.).

Charge-discharge measurement for the cells was conducted across both qualification tests using a computerized battery analyzer (ACD-01, Asuka Electronic Co., Ltd.) in constant-current/constantvoltage $(\mathrm{CC} / \mathrm{CV})$ mode during charging and $\mathrm{CC}$ mode during discharging in the voltage range of $2.8-4.0 \mathrm{~V}$. The end of the $\mathrm{CV}$ mode was established as $1 / 10$ of the set current value. The test cells were located in a thermally controlled chamber connected to the battery analyzer.

\subsection{Qualification test for the satellite with the FM cell}

We selected a 1.0 Ah pouch LIB cell using the LiFSI/MPPyrFSI electrolyte as an FM cell for the satellite. The two pouch cells were utilized without reinforcement and were located on the wall surface of the demonstration module box (Fig. 3a). The KAPTON ${ }^{\circledR}$ tape covering the pouch cell was used for the double insulation of the electrical conduction. Furthermore, it also eliminates the risk of adverse influences on other equipment due to unexpected outgassing or electrolyte leakage and to prevent discharge caused by static 
Table 4. ${ }^{60} \mathrm{Co}$ irradiation influences for discharge capacity, coulombic efficiency, and capacity retention for three IL-LIBs.

\begin{tabular}{|c|c|c|c|c|c|c|}
\hline \multirow{2}{*}{$\begin{array}{l}\text { Electrolyte } \\
{ }^{60} \mathrm{Co} / \mathrm{krad} \\
\end{array}$} & \multicolumn{2}{|c|}{ LiTFSI/EMImFSI } & \multicolumn{2}{|c|}{ LiFSI/EMImFSI } & \multicolumn{2}{|c|}{ LiFSI/MPPyrFSI } \\
\hline & 12 & 0 & 12 & 0 & 12 & 0 \\
\hline $\begin{array}{l}\text { Discharge capacity* } \\
\qquad / \mathrm{mAh}\end{array}$ & 357.1 & 354.4 & 355.1 & 355.1 & 399.2 & 398.4 \\
\hline $\begin{array}{c}\text { Coulombic efficiency* } \\
\qquad / \%\end{array}$ & 99.2 & 99.3 & 99.1 & 99.2 & 99.5 & 99.5 \\
\hline $\begin{array}{c}\text { Capacity retention }{ }^{*, \dagger} \\
\qquad \%\end{array}$ & 95.5 & 95.6 & 95.4 & 95.5 & 95.0 & 94.5 \\
\hline \multicolumn{7}{|c|}{$\begin{array}{l}{ }^{*} \text { Discharge capacity and Coulombic efficiency were evaluated by } 0.2 / 0.2 \mathrm{C} \text {-rate charge- } \\
\text { discharge cycling in a voltage range from } 2.7-4.2 \mathrm{~V} \text { at } 25^{\circ} \mathrm{C} \text {. } \\
{ }^{\dagger} \text { Capacity retention is defined as } C_{\mathrm{d}} / C_{\mathrm{d}}{ }^{0} \text {, where } C_{\mathrm{d}} \text { and } C_{\mathrm{d}}{ }^{0} \text { are the specific discharge } \\
\text { capacities measured at the time immediately following the irradiation test and at the time } \\
\text { of shipping, respectively. }\end{array}$} \\
\hline
\end{tabular}

electricity generated by the rubbing of the two batteries. Figure $3 b$ shows a block diagram of the battery evaluation system installed in the demonstration module. The power unit, which was constructed by connecting two ionic liquid-based $1.0 \mathrm{Ah}$ cells in series, can be charged by the electric power generated by a solar array. Then, the voltage of the charging battery was applied to the ohmicresistance heating $(100 \Omega)$ by series-switching regulators SW3 and SW4.

The power unit on the demonstration module was activated to confirm charge-discharge behavior and line impedance in the circuit by comparing it to the charge-discharge behavior of an identical $1.0 \mathrm{Ah}$ cell on the ground. Finally, the satellite with the cells went through several preliminary tests prior to launch. These included a heat cycle test in a thermal chamber (ISAS/JAXA), a vibration test (Kyushu Institute of Technology), a vacuum test (Kyushu Institute of Technology), and an environmental test with a pseudo solar light irradiation device (ISAS/JAXA).

\subsection{In-orbit operation}

After the successful launch and initial basic in-orbit operations of "Hodoyoshi-3," evaluation of the power unit began on July 24, 2014. After conducting several trial operations, a relatively long charge-discharge operation was executed on October 29, 2014. The trial operations involved measuring open voltage before operation and then applying a constant current of $0.2 \mathrm{~A}$ for $20 \mathrm{~min}$ to charge the power unit. After $5 \mathrm{~min}$, the unit was discharged to a load resistor $(100 \Omega)$ for $30 \mathrm{~min}$, where the corresponding current approximately $70 \mathrm{~mA}$ flowed in the circuit, as shown in Fig. 3b. Note that the obtained voltage data for the in-orbit power unit were corrected if necessary because they may contain an error of maximum $60 \mathrm{mV}$ because of fluctuation of the ground voltage. The operation temperature of the power unit, which was monitored by a thermocouple set between two cells, changed frequently in relation to the operational conditions of neighboring equipment and the time of day (i.e., day or night).

All results of the in-orbit power unit operation were analyzed using translated telemetry data.

\section{Results and Discussion}

\subsection{Radiation tolerance of IL-LIBs}

Because room temperature ionic liquids contain organic ions, concerns that ionic liquids will decompose under high-level radiation persist. Shkrob et al. have reported the radiation stability of ionic liquids with reference to their application to nuclear fuel processing. ${ }^{41-43}$ Sulfonyl imide anions typified by bis(trifluoro- methylsulfonyl)imide, whose structure contains $-\mathrm{SO}_{2}-\mathrm{N}^{\ominus}$, can be easily oxidized through production of an imidyl radical $\left(\mathrm{CF}_{3} \mathrm{SO}_{2} \mathrm{~N} \bullet\right)$, which usually involves chain radiolysis of ionic liquids. ${ }^{41,42}$ An irreversible radiolytic reaction of alkylated ammonium cations (and perhaps other aliphatic cations) can occur through elimination of their alkyl chain in a high-dose environment. ${ }^{41}$ Even alkylated imidazolium cations, one of the typical aromatic cations comprising many ionic liquids, can decompose radiolytically via several degradation pathways. ${ }^{43}$ It is important to understand ionic liquids' radiation stabilities in space environment because they are now investigated for aiming at the application of not only batteries but also other space technology, such as space propulsion, ${ }^{44-47}$ space lubricants, ${ }^{48-50}$ and artificial muscles. ${ }^{51}$

We did not observe any apparent change in shape and volume for three cells. The charge-discharge curves of the three $0.4 \mathrm{Ah}$ cells with different electrolytes (LiFSI/EMImFSI, LiTFSI/EMImFSI, and LiFSI/MPPyrFSI), which were obtained after the 12-krad radiation tolerance test are shown in Fig. 4. The charge-discharge curves of the corresponding cells not subjected to the irradiation test are shown for comparison. All cells exhibited typical behavior for an NMC-based cell having voltage gradient in its charge and discharge curves, which often helps assess the residual capacity and deterioration of the cells in terms of the satellite's power source management. The curves for the three cells subjected to the irradiation test are consistent with those for the corresponding notirradiated cells. Table 4 summarizes the irradiation influence on discharge capacity, coulombic efficiency, and capacity retention against the initial capacity of the three cells. The irradiated cells exhibited specific discharge capacity of 357-399 mAh, with Coulombic efficiency greater than $99 \%$. These values are approximately equivalent to the corresponding not irradiated cells. The initial specific discharge capacities of the cells with EMImFSI-based electrolytes lost approximately $40 \mathrm{mAh}$ when compared to the designed capacity. This is attributed to the relatively large irreversible capacity during formation cycling caused by irreversible intercalation/decomposition of EMIm ${ }^{+}$into/on the edge surface of the graphite. ${ }^{37}$ Furthermore, the bulky and electrochemically stable $\mathrm{MPPyr}^{+}$cation can prevent its insertion/decomposition to/on a graphite negative electrode, effectively reducing irreversible capacity loss. However, this result proved that ionic liquids in a pouch cell are stable in relation to the radiation irrespective of the constituent cations, presumably because the radiation dose of $12 \mathrm{krad}$ is significantly lower than the reported dose, which causes radiolysis of ionic liquids (over $0.1 \mathrm{Mrad}$ ). ${ }^{41}$ It should also be considered that current collectors for both electrodes and the aluminum laminate exterior might reduce radiation dose. 

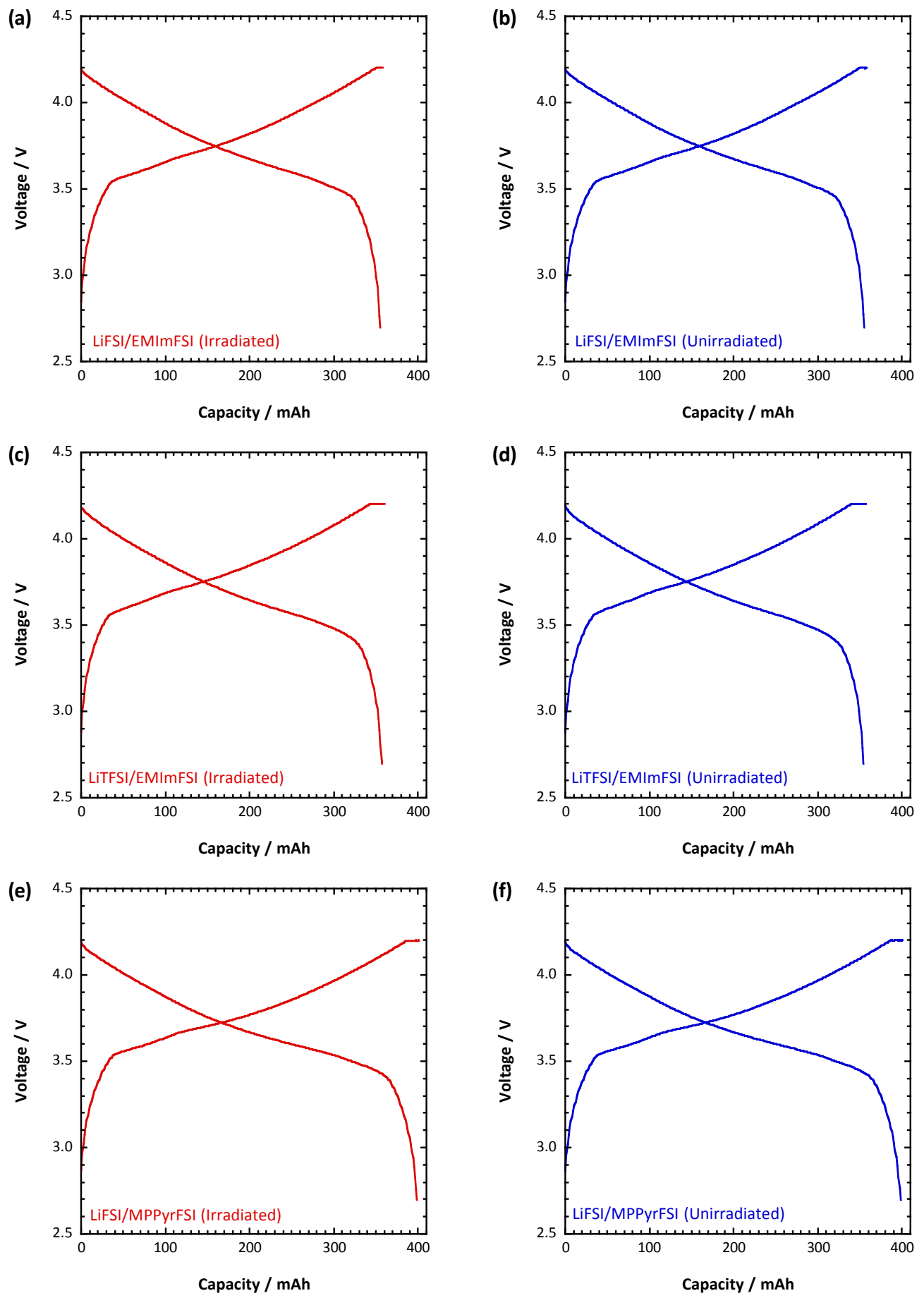

Figure 4. (Color online) Charge-discharge curves of three IL-LIB cells $(0.4 \mathrm{Ah})$ containing $(\mathrm{a}, \mathrm{b})$ LiFSI/EMImFSI, (c, d) LiTFSI/ EMImFSI, and (e, f) LiFSI/MPPyrFSI with (a, c, e) and without (b, d, f) 12 -krad irradiation $\left({ }^{60} \mathrm{Co}\right)$. The cells were evaluated at $0.2 / 0.2 \mathrm{C}$ charge-discharge in a voltage range of $2.7-4.2 \mathrm{~V}$.

\subsection{Vacuum test for the IL-LIB cell}

To characterize deformation of an IL-LIB cell and leakage of its components, a vacuum exposure test for the $1.0 \mathrm{Ah}$ cell was performed under deep vacuum conditions, i.e., less than $10^{-4} \mathrm{~Pa}$, which corresponds to conditions expected in low earth orbit. The appearance of the pouch cell was not altered under such conditions, except for some swelling that made the original wrinkles on the laminate package unnoticeable. This small deformation is due to expansion of air that could not be removed during the construction of the cell under relatively low pouching vacuum conditions (approximately $10^{-2} \mathrm{~Pa}$ ). After evaporation for $80 \mathrm{~h}$, the cell exhibited an impedance of $6.8 \mathrm{~m} \Omega$ at a constant frequency of
$1 \mathrm{kHz}$, which is nearly the same as the impedance of an intact cell $(6.7 \mathrm{~m} \Omega)$. However, charge-discharge measurement of $0.2 \mathrm{C}$ rate reveals that the discharge capacity of the evaporated cell maintained at $941 \mathrm{mAh}$, which is $89.5 \%$ of the initial capacity, while the discharge capacity retention of the intact cell relative to its initial discharge capacity was $91.8 \%$. Consequently, it is evident that little expansion of the pouch cell under high vacuum conditions has a slightly adverse effect on its charge-discharge characteristics.

\subsection{Charge-discharge operation in orbit}

Most particular conditions in space are low pressurized microgravity circumstances. Under the low pressurized conditions, most 


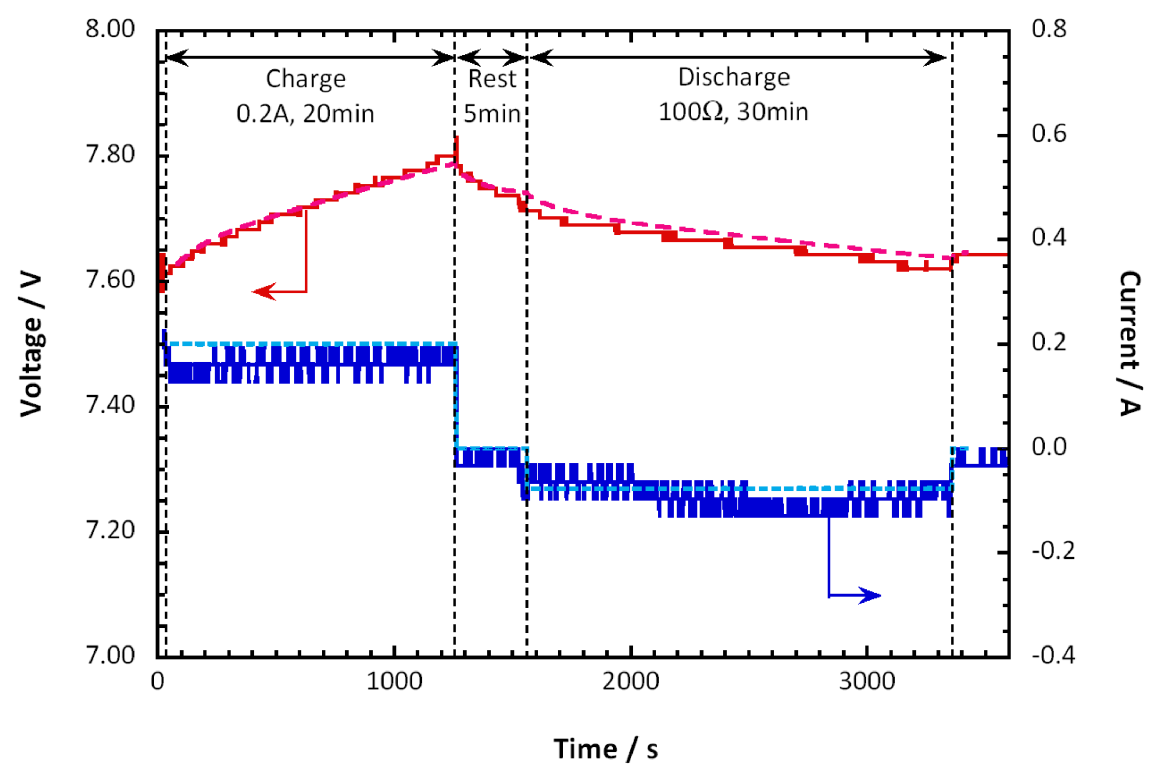

Figure 5. (Color online) Voltage-time and current-time curves of the power unit composed of two IL-LIB cells during charge-discharge operation in orbit (solid lines). The open-circuit voltage before power unit operation was measured. Then, constant current of $0.2 \mathrm{~A}$ was applied for $20 \mathrm{~min}$ to charge the power unit. After $5 \mathrm{~min}$, the unit was discharged to a load resistor $(100 \Omega)$ for 30 min. The curves predicted a charge-discharge ground test of an identical cell is also shown as dotted lines.

of the solvents are evaporated. In particular, in the case of the conventional lithium-ion secondary cells, the solvents are organic materials with higher vapor pressure, and expansion of the cell case is sometimes observed under the vacuum conditions. The expansion of the cell case may cause the lower electric contact between the electrode and electric solvent, which affect the increase in the impedance of the cell. Furthermore, microgravity may cause the loose contact between the solid and liquid. In any case on the ground, solvent receive the gravitational force, which ensure the contact with the solid materials. People sometimes operate the tests that simulate the gravity effect by changing the gravity direction.

Before discussing the in-orbit operation of the power unit, it should be noted that the satellite with the FM model of IL-LIB cells underwent and passed all qualification tests required prior to launch and flight, including a heat cycle test, a vibration test, a vacuum test, and an environmental test with a pseudo solar light irradiation device. The qualification tests results proved that the IL-LIB cells had sufficient tolerances for space use even without rigid antivacuum reinforcement.

Two months after the successful launch, we initiated the in-orbit operation of the power unit and monitored its open-circuit voltage (OCV). The first OCV data for the power unit at the 143rd operation of the satellite on July 24, 2014 was $7.07 \mathrm{~V}$ with a cell temperature of $0^{\circ} \mathrm{C}$, which was slightly lower than the final voltage obtained in the qualification tests (approximately $7.16 \mathrm{~V}$ ). The slight reduction was presumably caused by self-discharging. However, considering the elapsed time of three months after the qualification tests, it is evident that the cells could exist stably in a high-vacuum space environment.

Subsequently, a preliminary short-term charge-discharge operation was performed during the 192nd operation on August 5, 2014, followed by a long-term charge-discharge operation test conducted during the 528th operation on October 28. To the best of our knowledge, this was the first time an IL-LIB was successfully charged and discharged in orbit. The downlinked information from the satellite revealed that the temperature near the power unit was maintained at approximately $15^{\circ} \mathrm{C}$. Figure 5 summarizes both voltage and corresponding current transitions for the unit during the operation. The voltage curve for the in-orbit power unit shown in the figure was corrected to eliminate the effect of ground voltage fluctuation. The power unit exhibited an average OCV of approximately $7.60 \mathrm{~V}$. A gradual increase to $7.81 \mathrm{~V}$ was observed when the power unit was charged by a constant current of approximately $0.20 \mathrm{~A}$. After $5 \mathrm{~m}$, the unit voltage fell to $7.73 \mathrm{~V}$. Then, the unit was gradually discharged to $7.62 \mathrm{~V}$, generating a current of $60-100 \mathrm{~mA}$. Here we discuss the condition of the IL-LIB cells in flight by collating the in-orbit result with charge-discharge behavior of an identical IL-LIB cell on the ground. First, a state of charge (SOC) of the in-orbit IL-LIB cells was determined by comparing OCV for the in-orbit cell with that for a ground cell at a certain SOC because it is difficult to accurately grasp the SOC of the in-orbit IL-LIB cells after being left for a long time since the satellite was launched. (In this report, $100 \%$-SOC is defined when a cell is fully charged with the constant-current-constant-voltage (C.C.-C.V.) charging method at $0.5 \mathrm{~A}$. In the C.V. mode, the voltage has been kept constant at $4.0 \mathrm{~V}$ until the current reached a $0.01 \mathrm{~A}$.) As shown in Fig. 5, the in-orbit result closely agrees with the curve predicted by the ground test for an identical $1.0 \mathrm{Ah}$ cell with $84 \%$-SOC measured at $15^{\circ} \mathrm{C}$. Comparing both voltage curves, negligible increase in DC impedance for the in-orbit power unit can be seen even in a high-vacuum and microgravity environment, suggesting that components in the cells still contact rigidly even using the laminate exterior. Regarding the discharge curve for the in-orbit power unit, there was a very slight decrease in voltage, presumably caused by a 35 -s false start for in-orbit operation due to inaccuracy of the satellite's internal timer in addition to an increase in a discharge current observed at 2000 seconds for in-orbit data that was responsible for warming the ohmic resistance heater. Overall, the inorbit operation test suggests that the IL-LIB cell can operate stably in high-vacuum and microgravity environments.

\section{Conclusions}

Prototype lithium-ion pouch cells using FSI-based ionic liquids were designed for space applications and were evaluated for radiation and vacuum tolerance. The IL-LIB cells passed a 12-krad irradiation test that simulated one year of exposure to cosmic radiation and showed no deterioration in an ultra-high vacuum test even without rigid reinforcement. A prototype cell with the LiFSI/MPPyFSI electrolyte was installed as a power unit in a 
demonstration module on the "Hodoyoshi-3" satellite and was the first IL-LIB to be successfully charged and discharged in orbit. Results indicate that this IL-LIB demonstrates performance values equal to those of an identical cell on the ground and can exist stably in space with a flexible aluminum laminate exterior. The IL-LIB cells endured severe conditions, such as high g-forces and extreme vibration during rocket launch, and demonstrated no deterioration other than that which similarly occurred in the battery that remained on the ground. Successful charge-discharge operation of the IL-LIB is also extremely significant to further advancing satellite designs as well as various space applications. The use of nonvolatile and liquidus ionic liquid electrolytes enables the use of lightweight, thin, compact, and high-performance batteries without rigid housing or potting, which has been unavoidable in conventional batteries for space.

\section{Acknowledgments}

Part of this work, including the installation of the IL-LIB cell in the "Hodoyoshi-3" satellite and its operation in orbit, was supported by the Japan Society for the Promotion of Science through the "Funding Program for World-Leading Innovative R\&D on Science and Technology (FIRST Program)," initiated by the Council for Science and Technology Policy.

\section{References}

1. B. Scrosati, Nature, 373, 557 (1995).

2. S. Megahed and B. Scrosati, J. Power Sources, 51, 79 (1994).

3. M. Wakihara, Mater. Sci. Eng. R Reports, 33, 109 (2001).

4. M. S. Vreeke, D. T. Mah, and C. Mare Doyle, J. Electrochem. Soc., 145, 3668 (1998).

5. J. Van Mierlo and G. Maggetto, Fuel Cells, 7, 165 (2007).

6. F. T. Wagner, B. Lakshmanan, and M. F. Mathias, J. Phys. Chem. Lett., 1, 2204 (2010).

7. M. J. Barnsley, J. J. Settle, M. a. Cutter, D. R. Lobb, and F. Teston, IEEE Trans. Geosci. Remote Sens., 42, 1512 (2004).

8. C. Pearson, C. Thwaite, and N. Russel, 3rd Responsive Space Conference, RS32005-5003, Los Angeles, CA, USA (2005).

9. M. C. Smart, B. V. Ratnakumar, and S. Surampudi, J. Electrochem. Soc., 149, A361 (2002).

10. Y. Sone, H. Ooto, M. Kubota, M. Yamamoto, H. Yoshida, T. Eguro, S. Sakai, T. Yoshida, M. Uno, K. Hirose, M. Tajima, and J. Kawaguchi, Electrochemistry, 75, 518 (2007).

11. Y. Sone, H. Ooto, T. Eguro, T. Yoshida, M. Kubota, H. Yoshida, M. Yamamoto, S. Sakai, K. Ogawa, Y. Takeda, M. Uno, K. Hirose, M. Tajima, and J. Kawaguchi, Electrochemistry, 75, 950 (2007).

12. M. Uno, K. Ogawa, Y. Takeda, Y. Sone, K. Tanaka, M. Mita, and H. Saito, J. Power Sources, 196, 8755 (2011).

13. B. V. Ratnakumar, M. C. Smart, A. Kindler, H. Frank, R. Ewell, and S. Surampudi, J. Power Sources, 119-121, 906 (2003).

14. B. V. Ratnakumar, M. C. Smart, L. D. Whitcanack, and R. C. Ewell, J. Power Sources, 159, 1428 (2006).

15. B. V. Ratnakumar, M. C. Smart, L. D. Whitcanack, K. B. Chin, R. C. Ewell, S. Surampudi, F. Puglia, and R. Gitzendanner, 3rd International Energy Conversion Engineering Conference, American Institute of Aeronautics and Astronautics, Reston, Virigina (2005).

16. H. Shiraishi, S. Tanaka, A. Fujimura, and H. Hayakawa, Adv. Sp. Res., 42, 386 (2008).

17. E. Darcy, J. Power Sources, 174, 575 (2007)
18. M. Armand, F. Endres, D. R. MacFarlane, H. Ohno, and B. Scrosati, Nat. Mater, 8, 621 (2009).

19. M. Galinski, A. Lewandowski, and I. Stepniak, Electrochim. Acta, 51, 5567 (2006).

20. R. T. Carlin, J. Fuller, and M. Hedenskoog, J. Electrochem. Soc., 141, L21 (1994).

21. N. Koura, K. Etoh, Y. Idemoto, and F. Matsumoto, Chem. Lett., 30, 1320 (2001).

22. S. Seki, Y. Kobayashi, H. Miyashiro, Y. Ohno, Y. Mita, A. Usami, N. Terada, and M. Watanabe, Electrochem. Solid-State Lett., 8, A577 (2005).

23. S. Seki, Y. Kobayashi, H. Miyashiro, Y. Ohno, A. Usami, Y. Mita, M. Watanabe, and N. Terada, Chem. Commun., 2006, 544 (2006).

24. T. Sato, T. Maruo, S. Marukane, and K. Takagi, J. Power Sources, 138, 253 (2004).

25. M. Holzapfel, C. Jost, and P. Novák, Chem. Commun., 2004, 2098 (2004).

26. H. Zheng, K. Jiang, T. Abe, and Z. Ogumi, Carbon, 44, 203 (2006).

27. M. Nádherná, J. Reiter, J. Moškon, and R. Dominko, J. Power Sources, 196, 7700 (2011).

28. J. Reiter and M. Nadherna, Electrochim. Acta, 71, 22 (2012)

29. V. Chakrapani, F. Rusli, M. A. Filler, and P. A. Kohl, J. Phys. Chem. C, 115, 22048 (2011).

30. K. Nishikawa, T. Ojima, M. Kawase, and H. Naito, IEICE Technical Report. Component Parts and Materials, 111(434), 9 (2012). [in Japanese]

31. M. Ishikawa, T. Sugimoto, M. Kikuta, E. Ishiko, and M. Kono, J. Power Sources, 162, 658 (2006).

32. T. Sugimoto, M. Kikuta, E. Ishiko, M. Kono, and M. Ishikawa, J. Power Sources, 183, 436 (2008).

33. T. Sugimoto, Y. Atsumi, M. Kono, M. Kikuta, E. Ishiko, M. Yamagata, and M. Ishikawa, J. Power Sources, 195, 6153 (2010).

34. Y. Matsui, S. Kawaguchi, T. Sugimoto, M. Kikuta, T. Higashizaki, M. Kono, M. Yamagata, and M. Ishikawa, Electrochemistry, 80, 808 (2012).

35. M. Yamagata, Y. Matsui, T. Sugimoto, M. Kikuta, T. Higashizaki, M. Kono, and M. Ishikawa, J. Power Sources, 227, 60 (2013).

36. Y. Matsui, M. Yamagata, S. Murakami, Y. Saito, T. Higashizaki, E. Ishiko, M. Kono, and M. Ishikawa, J. Power Sources, 279, 766 (2015).

37. M. Yamagata, N. Nishigaki, S. Nishishita, Y. Matsui, T. Sugimoto, M. Kikuta, T. Higashizaki, M. Kono, and M. Ishikawa, Electrochim. Acta, 110, 181 (2013).

38. M. Yamagata, M. Hirayama, S. Nishishita, D. Horikawa, and M. Ishikawa, Electrochemistry, 81, 857 (2013).

39. A. Enokuchi, N. Takeyama, Y. Nakamura, Y. Nojiri, N. Miyamura, A. Iwasaki, and S. Nakasuka, Proc. SPIE 7862, Earth Observing Missions and Sensors: Development, Implementation, and Characterization, 78620B (2010); doi:10.1117/12.869499.

40. K. Maeda and S. Nakasuka, Geoscience and Remote Sensing Symposium (IGARSS), 2014 IEEE International, p. 3630 (2014), doi:10.1109/IGARSS. 2014.6947269.

41. I. A. Shkrob, S. D. Chemerisov, and J. F. Wishart, J. Phys. Chem. B, 111, 11786 (2007).

42. I. A. Shkrob, T. W. Marin, S. D. Chemerisov, J. Hatcher, and J. F. Wishart, J. Phys. Chem. B, 116, 9043 (2012).

43. I. A. Shkrob, T. W. Marin, S. D. Chemerisov, and J. F. Wishart, J. Phys. Chem. B, 115, 3872 (2011).

44. Y.-H. Chiu and R. a Dressler, in ACS Sympsium Series: Ionic Liquids IV, p. 138 (2007).

45. R. P. Singh, R. D. Verma, D. T. Meshri, and J. M. Shreeve, Angew. Chem., Int. Ed., 45, 3584 (2006).

46. M. Smiglak, A. Metlen, and R. D. Rogers, Acc. Chem. Res., 40, 1182 (2007).

47. F. Kamal, B. Yann, B. Rachid, and K. Charles, in Applications of Ionic Liquids in Science and Technology, S. Handy, Editor, p. 447, InTech (2011).

48. C. Ye, W. Liu, Y. Chen, and L. Yu, Chem. Commun., 2244 (2001).

49. M. D. Bermúdez, A. E. Jiménez, J. Sanes, and F. J. Carrión, Molecules, 14, 2888 (2009).

50. A. Somers, P. Howlett, D. MacFarlane, and M. Forsyth, Lubricants, 1, 3 (2013).

51. A. Punning, K. J. Kim, V. Palmre, F. Vidal, C. Plesse, N. Festin, A. Maziz, K. Asaka, T. Sugino, G. Alici, G. Spinks, G. Wallace, I. Must, I. Põldsalu, V. Vunder, R. Temmer, K. Kruusamäe, J. Torop, F. Kaasik, P. Rinne, U. Johanson, A.-L. Peikolainen, T. Tamm, and A. Aabloo, Sci. Rep., 4, 6913 (2014). 